\title{
ANALISA KEKUATAN DAN KETANGGUHAN PADA PENGELASAN BERULANG PADA PIPA A350 LF2CL1 DAN API 5L X52
}

\section{STRENGTH AND TOUGHNESS ANALYSIS ON REPAIR WELDING BETWEEN PIPE A350 LF2CL1 AND API 5L X52}

\author{
Buyung Nul Hakim \\ Teknik Mesin,Fakultas Teknik,Universitas Riau Kepulauan, Batam, Indonesia \\ buyung.buy@gmail.com
}

\begin{abstract}
Abstrak
Pada penelitian ini dilakukan percobaan dengan mengunakan pipa berbeda yang telah mengalami pengelasan berulang sebanyak satu kali dengan proses pengelasan awal Flux Core Arc Welding (FCAW) dan proses repair menggunakan Shield Metal Arc Welding (SMAW), kemudianakan dilakukan uji tarik, uji makro, uji impak, uji kekerasan dan Scanning Electron Microscopic (SEM). Tujuannya untuk mengetahui apakah sambungan pipa ini memenuhi persyaratan dari peraturan DNVGL ditinjau dari aspek kekuatan tarik, impak dan ketangguhan. Metode pengujian material akan dilakukan untuk melihat hasil yang menggambarkan kekuatan dan karakteristik material. Sampel bahan uji berupa spesimen yang menggunakan standar AWS D1.1. Sifat beban yang diberikan mencakup beban statis untuk uji tarik, uji kekerasan dan uji impact sedangkan uji makro untuk melihat secara visual bentukdaripengelasan. Hasilpenelitianiniberupanilaikekuatan material yang kemudian dibandingkan dengan nilai minimum persyaratan DNVGL. Beberapa hasil seperti penampang patahan juga dapat mewakili karakter keuletan material. Hasil yang dicapai bahwa sambungan pipa ini memenuhi persyaratan DNVGL ditinjau dari kekuatan tarik (510Mpa), kekuatan impak rata-rata di atas 27J pada suhu $46^{\circ} \mathrm{C}$
\end{abstract}

Keywords :Flux Core Arc Welding (FCAW), Shield Metal Arc Welding (SMAW, Scanning Electron Microscopic (SEM)

\begin{abstract}
In this experiment, experiments using different pipes have undergone repeated welding once with the initial welding process of Flux Core Arc Welding (FCAW) and repair process using Shield Metal Arc Welding (SMAW), then tensile test, macro test, test impact, hardness test and Scanning Electron Microscopic (SEM). The objective is to know whether the pipeline connection meets the requirements of DNVGL regulations in terms of tensile strength, impact and toughness. Material testing methods will be performed to see results that illustrate the strength and characteristics of the material. Samples of test materials in the form of specimens using AWS standard D1.1. Load properties include static load for tensile test, hardness test and impact test while macro test to see visually the shape of welding.

The result of this research is material strength value which is then compared with minimum value of DNVGL requirement. Some results such as fault cross section can also represent the material's ductility character. The results achieved that this pipe joint meets the DNVGL requirements in terms of tensile strength (510 Mpa), average impact strength above $27 \mathrm{~J}$ at $-46^{\circ} \mathrm{C}$
\end{abstract}

Keywords: Flux Core Arc Welding (FCAW), Shield Metal Arc Welding (SMAW), Scanning Electron Microscopic (SEM) 


\section{PENDAHULUAN}

Pada proses perencanaan struktur baik itu di bidang perkapalan atau perminyakan pemilihan prosedur pengelasan mempunyai peranan yang sangat penting. Prosedur pengelasan ini (WPS) bertujuan untuk menentukan dimulai dari jenis kawat las yang akan digunakan untuk menyambung struktur sesuai dengan perencanaan struktur secara keseluruhan.

Fakta di lapangan sering dijumpai pekerjaan pengelasan tidak sempurna. Banyak terjadi cacat las dikarenakan faktor dari tukang las, lingkungan pengelasan, cuaca.

Untuk mengantisipasi hal tersebut, maka dibuat prosedur pengelasan perbaikan. Peraturan atau panduan untuk prosedur pengelasan yang diterbitkan oleh badan international tidak secara rinci membahas prosedur perbaikan pengelasan

\section{Tinjauan Pustaka}

Pengelasan adalah proses penyambungan antara dua bagian logam atau lebih dengan menggunakan energy panas, maka logam yang di sekitar daerah las mengalami perubahan struktur metalurgi, deformasi dan tegangan termal. Untuk mengurangi pengaruh tersebut, maka dalam proses pengelasan perlu diperhatikan metode dan prosedur pengelasan yang benar dan tepat, termasuk pemilihan bahan pengisi (filler) yang digunakan. Selain itu juga diharapkan kekuatan sambungan las sama dengan material baja yang disambung.

Sambungan las yang akan digunakan pada sambungan konstruksi baja harus memenuhi persyaratan yang ketat diantaranya adalah tegangan tarik dan ketangguhan harus mempunyai nilai tinggi, minimal 27 Joule pada suhu yang $-50^{\circ} \mathrm{C}$ atau 100 Joule pada suhu $0^{\circ} \mathrm{C}$.

Proses FCAW sangat sering digunakan dalam industri pengelasan. Terdapat beberapa nilai tambah dibandingkan dengan misal proses SAW atau GMAW.

\section{Input Panas}

Input panas adalah besarnya energy panas tiap satuan panjanglas ketika sumber panas bergerak.

Input panas $(\mathrm{H})$, dinyatakan dengan persamaan sebagai berikut:

$H=P / v=E I / v$

Dimana :

$\mathrm{P}$ : Tenaga input (watt)

$\mathrm{E}$ :Potensiallistrik (volt)

I :Aruslistrik (amper)

$\mathrm{v}:$ Kecepatan Las (m/s) 
Input panas juga mempengaruhi bentuk penampang lintang lasan (welding bead) yang meliputi besarnya permukaan logam induk yang mencair, permukaan bahan pengisi dan HAZ. Fungsi utama sumber panas pada las cair (fusion welding) adalah untuk mencairkan logam, yang mempunyai dua pengaruh, yaitu; pada pembentukan struktur mikrolas dan juga menimbulkan siklus termal daerah lasan.

\section{Siklus Termal Daerah Lasan}

Selama pengelasan berlangsung, logam las dan daerah pengaruh panas atau heat affected zone (HAZ) akan mengalami serangkaian siklus thermal, yaitu pemanasan sampai mencapai suhu maksimum kemudian diikuti dengan pendinginan. Siklus thermal tersebut mempengaruhi struktur mikro logam las dan HAZ, dimana logam akan mengalami serangkaian transformasi fasa selama proses pendinginan, yaitu dari logam las cair berubah menjadi Ferit- $\delta$ kemudian $\gamma$ (Austenit) dan akhirnya menjadi $\alpha$ (Ferrit). Pada umumnya waktu (cooling time) antara temperatur $800^{\circ} \mathrm{C}-500^{\circ} \mathrm{C}$ dipakai sebagai acuan pada pengelasan baja karbon, karena pada interval suhu tersebut terjadi trans-formasi fasa dari Austenit $(\gamma)$ menjadi Ferrite atau Bainite yang tergantung pada kecepatan pendinginannya. Besarnya waktu pendinginan dapat dihitung dengan persamaan berikut:

$\Delta t_{8 / 5}=\frac{\frac{q}{v}}{2 \pi k}\left[\frac{1}{500-T_{0}}-\frac{1}{800-T_{0}}\right]$

dimana:

$\Delta \mathrm{t}_{8 / 5} \quad$ : Waktu pendinginan antara $800{ }^{\circ} \mathrm{C}$ dan $500^{\circ} \mathrm{C}$

$\mathrm{T}_{0} \quad$ :Temperatur akhir las $\left({ }^{0} \mathrm{C}\right)$

q : Masukan panas $(\mathrm{kJ} / \mathrm{mm})$

$\mathrm{v} \quad$ : Kecepatan las $(\mathrm{mm} / \mathrm{s})$

$\mathrm{k} \quad$ : Konduktifitas termal $\left(\mathrm{J} / \mathrm{mm} . \mathrm{s}^{-1} \mathrm{~K}^{-1}\right)$

\section{Struktur Mikro Las}

Selama pendinginan dari logam cair sampai menuju suhu kamar, logam las mengalami serangkaian perubahan fasa. Baja karbon rendah (kandungan $\mathrm{C}<0,1 \%$ ) akan mengalami perubahan-perubahan fasa cair menjadi Ferrite $\delta$ ketika pembekuan berlangsung kemudian berubah menjadi Austenite $\gamma$ dan akhirnya menjadi Ferrite $\alpha$ dan Pearlite. Struktur mikro yang akan terbentuk ditentukan pada saat pendinginan. Ada beberapa faktor yang mempengaruhi struktur mikro, seperti komposisi akhir logam las, filler serta kondisi udara sekitar pengelasan. 
Proses pendinginan pada las berlangsung secara kontinu, yaitu proses penurunan suhu berlangsung tanpa adanya penurunan suhu secara mendadak. Proses pendinginan hasil pengelasan pada umumnya berlangsung secara cepat sehingga untuk menganalis struktur mikro hasil pengelasan tidak dapat digunakan diagram fasa. Diagram fasa hanya dapat dipergunakan untuk kondisi dimana laju pendinginan sangat lambat dan proses difusi atom berlangsung. Karena itu untuk menganalisis struktur mikro hasil pengelasan dapat digunakan diagram Continuous Cooling Transformation (CCT).

\section{Spesimen Uji}

Berdasarkan mill certificate yang dikeluarkan specimen uji mempunyai nilai:

1. Pipa API 5L Gr. X52 :

Ultimate Tensile Load : $543 \mathrm{MPa}$

Ultimate Tensile Stress : $434 \mathrm{MPa}$

Impact Test at $-50^{\circ} \mathrm{C}: 213 \mathrm{~J}$

2. Pipa ASTM A350 LF2 CL1 :

Ultimate Tensile Load : $504 \mathrm{MPa}$

Ultimate Tensile Stress : 307 MPa

Impact Test at $-46^{\circ} \mathrm{C}: 80.3 \mathrm{~J}$

3. Kawat las merek Kiswell K-71TSR (AWS A5.20-05) untuk proses FCAW :

Ultimate Tensile Load : $588 \mathrm{MPa}$

Ultimate Tensile Stress : $522 \mathrm{MPa}$

Impact Test at $-40^{\circ} \mathrm{C}: 120 \mathrm{~J}$

4. Kawat las merek Lincoln Jetweld LH-75MR (AWS5.1 E7018-1 H4R) untuk proses SMAW:

Ultimate Tensile Load : $568 \mathrm{MPa}$

Ultimate Tensile Stress :491 MPa

Impact Test at $-46^{\circ} \mathrm{C}: 154 \mathrm{~J}$

\section{MetodePenelitian}

Proses pengelasan yang dilakukan pertama ialah dengan proses FCAW, setelah dilakukan pengujian merusak. Sampel uji dilakukan gauging pada daerah kolam las FCAW kemudian dilakukan pengelasan SMAW sebagai perbaikan pengelasan. 


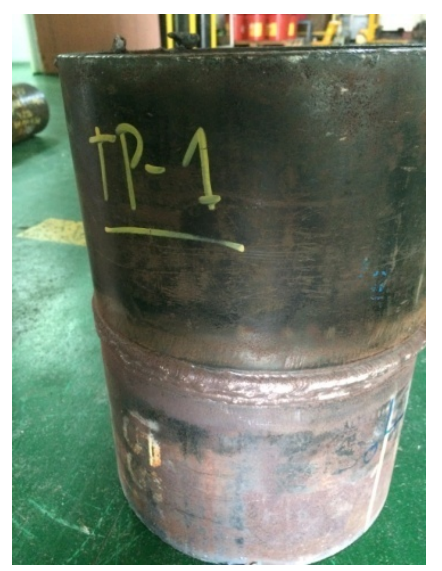

Gambar 1. Sampel uji

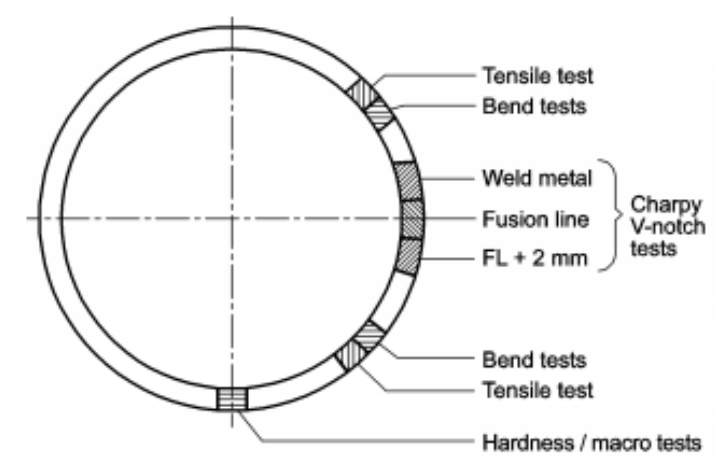

Gambar 2. Lokasi Pengambilan Spesimen Uji

\section{Hasil dan Pembahasan}

\section{$\underline{\text { Uji Makro }}$}

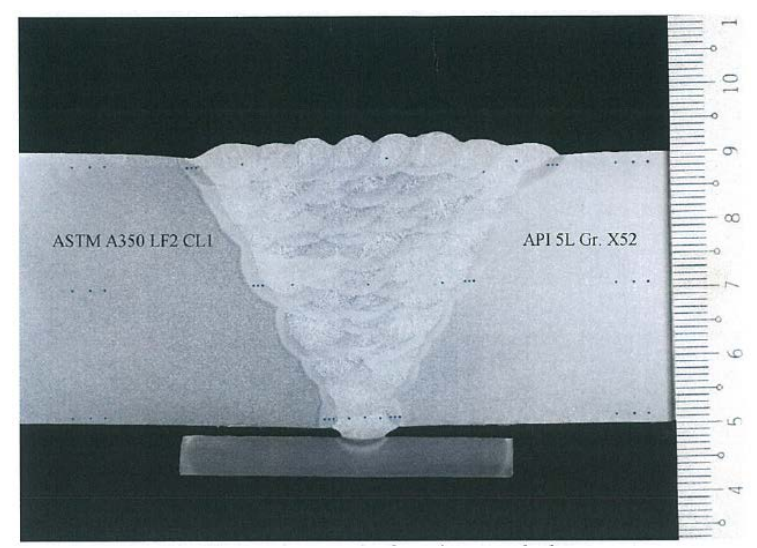

Gambar3. Spesimen uji makro proses FCAW 


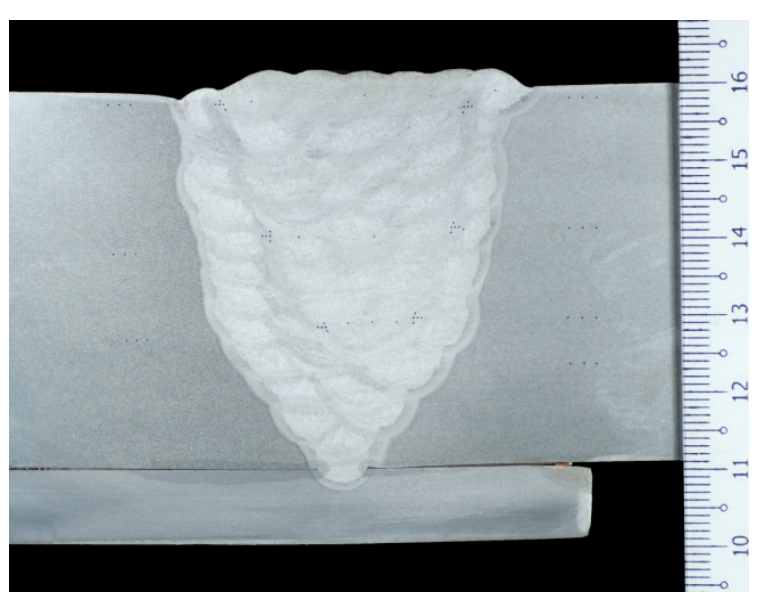

Gambar 4. Spesimen uji makro proses FCAW + SMAW

Uji makro untuk mengetahui gambaran struktur HAZ pada sambungan las Uji Tarik

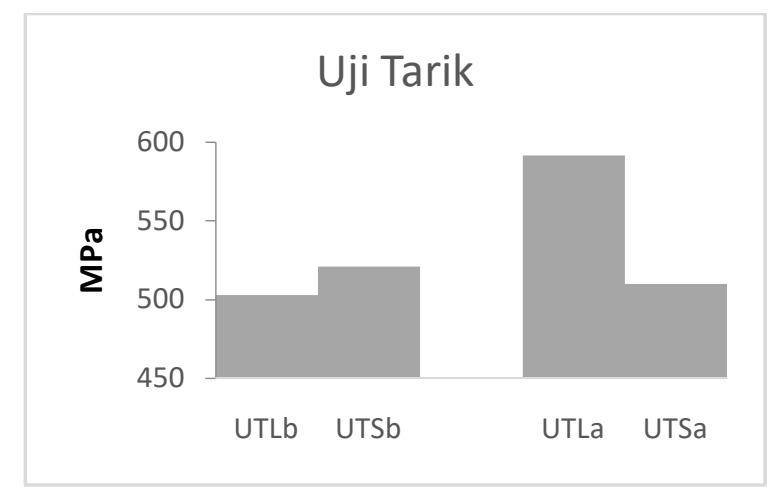

Tabel 1. Hasil uji tarik

Dari hasil uji tarik, sampel mengalami kenaikan dibandingkan dengan sebelum mengalami perbaikan atau dua kali pengelasan.

\section{Uji Impak}

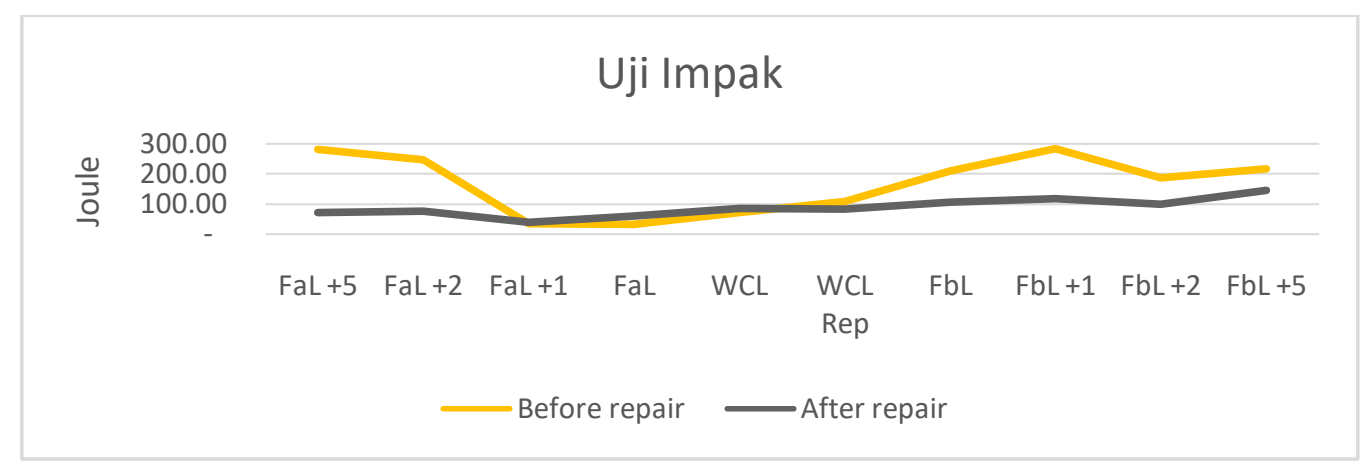

Tabel 2. Hasil uji impak pada suhu $-46^{\circ} \mathrm{C}$ 
Dari pengujian impak terlihat tingkat ketahanan semakin menurun setelah mengalami pengelasan berulang.

Uji Kekerasan

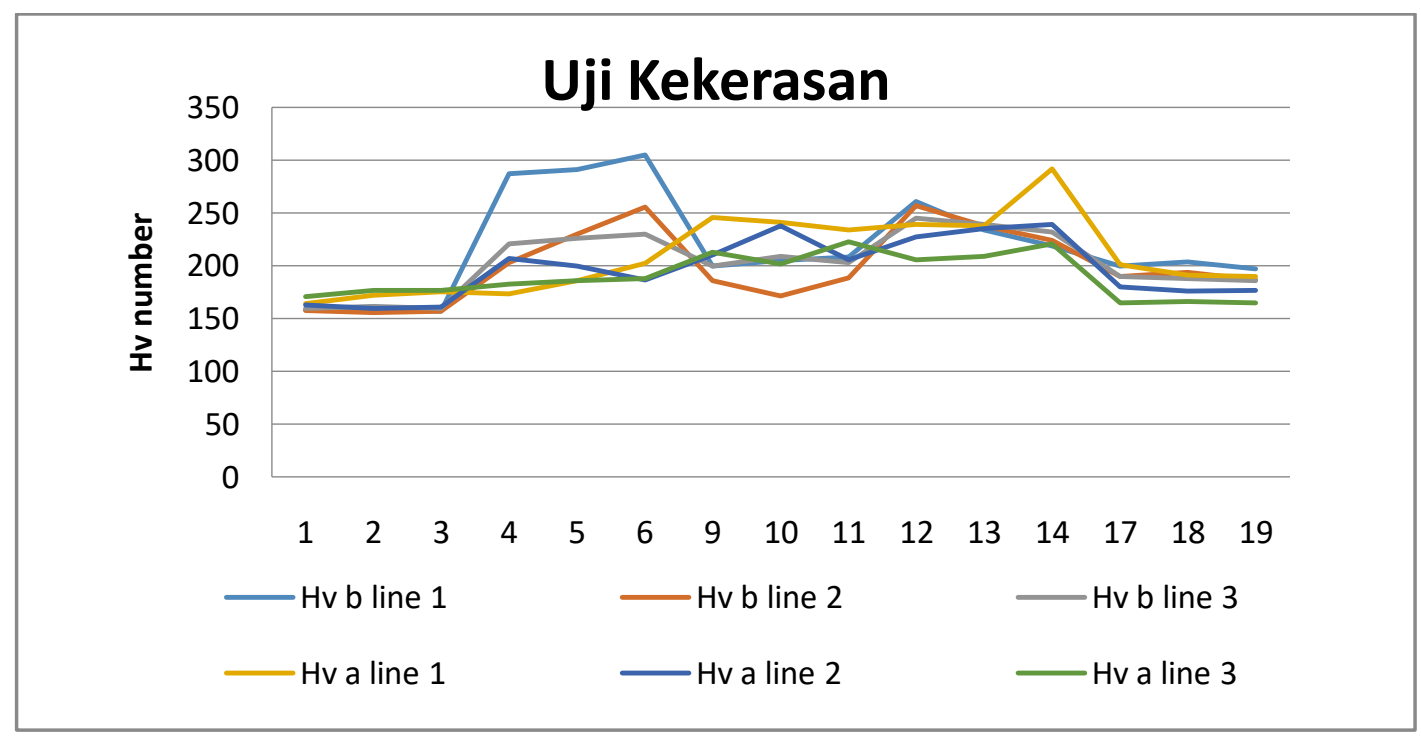

Table 3. Hasil uji kekerasan

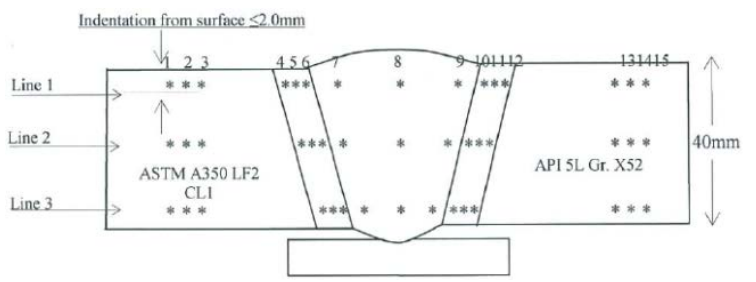

Gambar 5. Lokasi pengujian kekerasan

Terlihat dari pengujian kekerasan, tingkat kekerasan sebelum dan sesudah mengalami pengelasan berulang pada daerah kolam las tidak terdapat perubahan yang signifikan.

\section{Uji SEM}

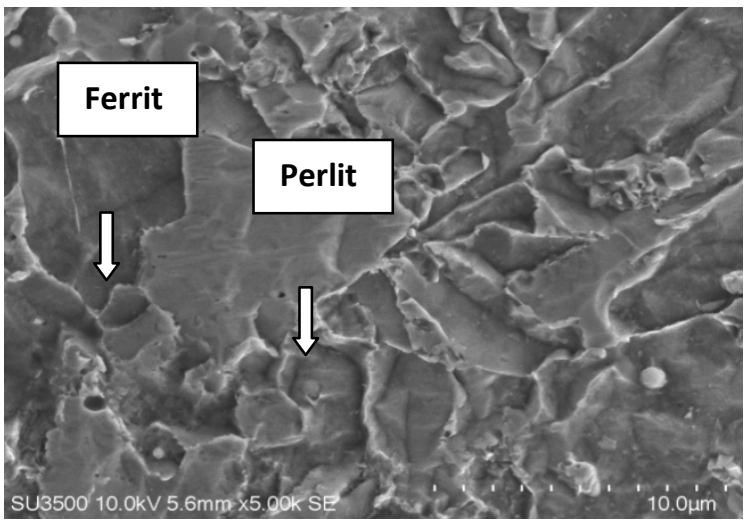

Gambar 6. Lokasi pada HAZ - proses welding FCAW 
Sebaran butiran pada gambar 6 memperlihatkan geometri bersudut akibat pendinginan di HAZ saat proses pengelasan, hal ini mempengaruhi pada kekerasan dan mampu impak.

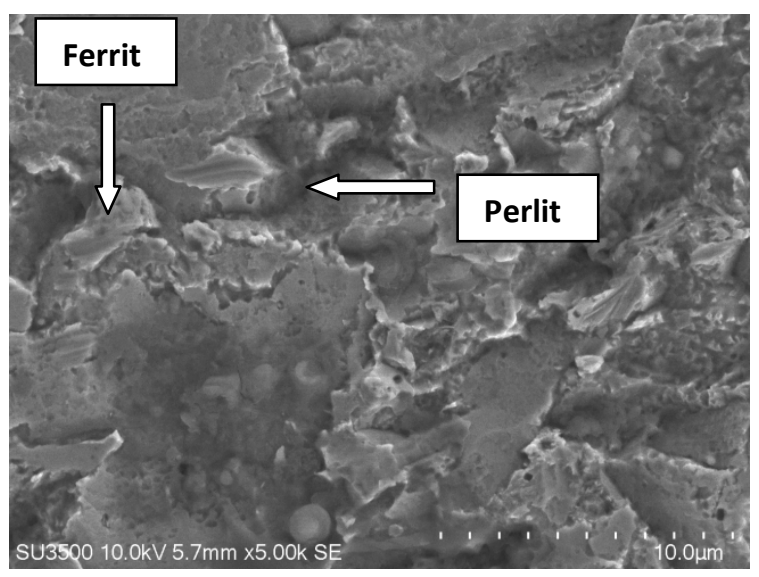

Gambar 7. Lokasi pada kolam las - proses welding FCAW

Pada kolam las geometri butiran mampu tumbuh lebih merata dan sudut-sudut tajam tidak banyak terlihat Gambar 7.

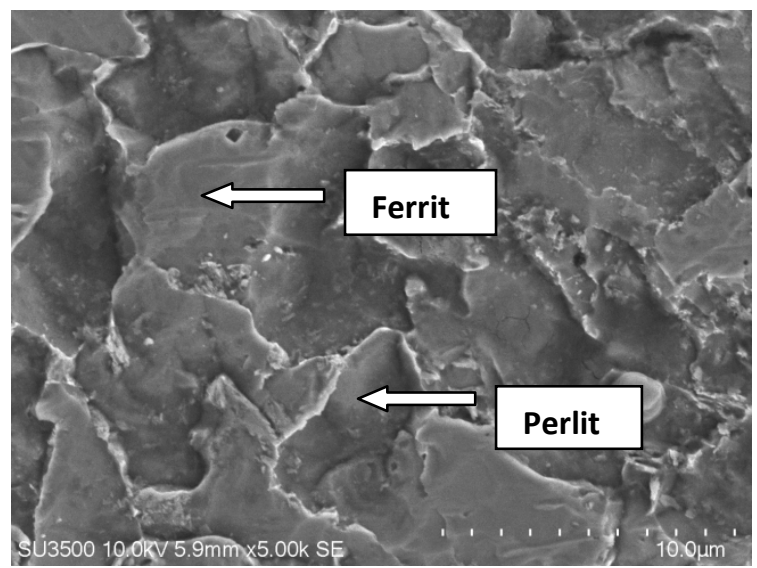

Gambar 8. Lokasi pada HAZ - proses welding SMAW

Geometri butiran menyudut namun tidak setajam pada HAZ FCAW Gambar 6.

\section{KESIMPULAN}

Dari hasil percobaan dan pengujian merusak di atas, dapat disimpulkan Yield strength setelah pengelasan dua kali mengalami kenaikan. Kemudian kekuatan impak mengalami penurunan dan kekerasan cenderung tidak berubah. Hal ini disebabkan daerah kolam las mengalami pemanasan yang berlebih dan juga pengamatan yang lain dapat terlihat dari struktur mikro yang terjadi ukuran butiran mengalami perubahan menjadi lebih besar. 


\section{DAFTAR PUSTAKA}

American Welding Society, Structural Welding Code- Steel AWS D1.1/D1.1M:2015, no. February. 2015.

DNVGL, “OFFSHORE STANDARDS, Metallic materials,” DNVGL-OS-B101, no. January, 2018.

DNVGL, "Fabrication and testing of offshore structures," DNVGL-OS-C401, no. January, 2018.

D. P. FAIRCHILD, N. V BANGARU, J. Y. KOO, P. L. HARRISON, and A. OZEKCIN, “A Study Concerning Intercritical HAZ Microstructure and Toughness in HSLA Steels,” Weld. J., vol. 70, no. 12, p. 321s-330s, 1991.

K. Poorhaydari, B. M. Patchett, and D. G. Ivey, "Estimation of Cooling Rate in the Welding of Plates with Intermediate Thickness,” Weld. J., vol. 84, no. 10, pp. 149-155, 2005.

M. Yuga, M. Hashimoto, and S. Suzuki, "Steel plates with excellent HAZ toughness for offshore structures,” JFE Tech. Rep., vol. 18, no. 18(Mar), pp. 43-49, 2013.

S. Kou, Welding Metallurgy Second Edition, vol. 822, no. 1-3. 2003.

S. A. Mohamat, I. A. Ibrahim, A. Amir, and A. Ghalib, “The effect of Flux Core Arc Welding (FCAW) processes on different parameters,” Procedia Eng., vol. 41, no. Iris, pp. 14971501, 2012.

S. Ragu Nathan, V. Balasubramanian, S. Malarvizhi, and A. G. Rao, "Effect of welding processes on mechanical and microstructural characteristics of high strength low alloy naval grade steel joints,” Def. Technol., vol. 11, no. 3, pp. 308-317, Sep. 2015. 